\title{
Analisis Variasi Jarak Sumbu Poros Terhadap Tegangan Kontak Dan Tegangan Bending Pada Helical Gear Pair Berdasarkan Metode Elemen Hingga
}

\author{
Sopyan Ali Rohman*, IDK Okariawan**, Achmad Zainuri** \\ Jurusan Teknik Mesin, Fakultas Teknik, Universitas Mataram \\ Jl. Majapahit no 62 Mataram
}

\begin{abstract}
This researchs object is determining the effect of modifying center distance to bending stress and contact stress on the helical gear pair based on the finite element method. And to know the safety factor on each center distance variation within helical gear pair.

Gear being analyzed is one of the gears on Honda motor cycles branded Beat. To know the specification of gear, the helical gear geometry measurements were taken. Based on the results of measurements was carried out models of helical gear pair by AUTO CAD software. Then, bending stress and contact stress analysis with finite element method on ANSYS 12.1. Optimal center distance of gear pairs is determined by safety factors on the quasi statatis condition.

From the research results can be concluded that the change of center distance can affect the bending stress and contact stress on gears and affect of security design. A safe center distance variation is $52.65 \mathrm{~mm}, 52,75 \mathrm{~mm}, 52,85 \mathrm{~mm}$ and $52.95 \mathrm{~mm}$.
\end{abstract}

Keywords: center distance, helical gear pair, safety factor, bending stress, contact stress

\section{Pendahuluan}

Perkembangan ilmu pengetahuan dan teknologi merupakan sebuah aspek kehidupan yang harus terpenuhi mengikuti perkembangan tarap hidup manusia. Kemajuan teknologi diberbagai bidang kehidupan manusia terdorong oleh semakin kompleknya kebutuhan manusia sehingga diharapkan penerapan teknologi dapat memberi banyak kemudahan dan manfaat bagi kehidupan manusia. Di samping itu, permintaan manusia selalu berubah-ubah dan keinginan manusia yang tidak terbatas menyebabkan para peneliti semakin gencar melakukan inovasi karya ciptanya, sehingga semakin efektif dan efisien serta memenuhi kebutuhan manusia.

Salah satu bidang teknologi yang kemajuannya cukup pesat dan ditunjang dengan permintaan pasar yang tinggi adalah teknologi otomotif khususnya sepeda motor jenis skuter matic (Vivanews, 2011). Teknologi sepeda motor saat ini, tidak terlepas dari peran salah satu elemen mesin yaitu roda gigi. Pada sepeda motor, daya yang dihasilkan oleh proses pembakaran setelah dikonversi menjadi gerak rotasi dengan mekanisme torak, ditransmisikan oleh pasangan roda gigi menuju poros-poros penggerak sebuah mekanisme tertentu sehingga sepeda motor dapat bergerak. Dalam mentransimisikan daya, gear mengalami tegangan bending dan tegangan kontak.
Berbagai metode analisis tegangan untuk keperluan perancangan elemen mesin telah banyak tersedia, salah satunya adalah metode elemen hingga. Metode elemen hingga telah membuktikan kehandalannya dalam memecahkan persoalan-persoalan dibidang mekanika. Bahkan dalam perkembangan yang terakhir, masalahmasalah perpindahan panas, mekanika fluida, maupun getaran dapat dengan mudah diselesaikan dengan menggunakan metode elemen hingga (Indrakto,2007).

Seiring dengan perkembangan teknologi komputer yang sangat pesat khususnya bidang software, mempengaruhi perkembengan software analisis tegangan berbasis metode elemen hingga. Salah satu perangkat lunak komputer yang dapat membantu dalam proses analisis tegangan dengan metode elemen hingga adalah software Ansys.

Penerapan perangkat lunak komputer pada permasalahan perancangan elemen mesin diharapkan meningkatkan kualitas dan keakuratan hasil analisis. Di samping itu, dapat mengurangi waktu analisis yang mempengaruhi nilai ekonomis elemen mesin yang dirancang.

Di dalam kehidupan sehari-hari, kesalahan dalam pemasangan roda gigi dan ketidakakuratan pada proses manufaktur mesin dapat menyebabkan terjadinya perubahan jarak pusat antara roda gigi yang berpasangan serta defleksi poros dalam 
penggunaannya dapat menyebabkan misalignment (Hotait, dkk.,2008). Perubahan jarak pusat tersebut memungkinkan terjadinya perubahan distribusi tegangan pada roda gigi yang berdampak pada ketahanan pakai material roda gigi. Di sisi lain, pengguna sepeda motor di Indonesia cukup tinggi, sehingga permintaan untuk perbaikan maupun perakitan sepeda motor pun cukup tinggi. Pada tahun 2011, angka penjualan Honda BEAT mencatat nilai tertinggi di kelas sepeda motor jenis sekuter matic (Vivanews, 2012).

Oleh karena itu, dalam penelitian ini dilakukan analisis tegangan bending dan tegangan kontak helical gear pair akibat penyimpangan jarak pusat menggunakan software ANSYS 12.1 pada salah satu helical gear pair Honda BEAT $110 \mathrm{cc}$.

\section{Tinjauan Pustaka}

Wei (2004) telah melakukan penelitian tentang karakteristik involute spur gear dan menyebutkan bahwa kegagalan pada gear sering kali terjadi karena tegangan kontak dan tegangan bending yang terjadi pada gigi gear tersebut. Patil dkk, (2011) menyebutkan bahwa dalam kondisi kerjanya, gear sering mengalami kegagalan karena konsentrasi tegangan dan tegangan bending pada tooth root, dimana pembentukan retak terjadi pada sekitar titik yang mengalami konsentrasi tegangan.

Wilfred Lewis (1892) mengajukan Lewis' formula untuk menganalisis tegangan bending pada gear, dimana gigi gear diasumsikan sebagai cantilever beam dengan beban aksial menyebabkan tegangan bending, sedangkan beban radial diabaikan (dikutip dari Khurmi dan Gupta, 1982). Bentuk gigi yang tidak dapat diasumsikan seperti cantilever beam yang polos, menyebabkan analisis tegangan bending dengan persamaan Lewis kurang akurat, sehingga berkembang dengan eksperimen photoelastic, dan seiring dengan perkembangan komputer, maka analisis tegangan dilakukan menggunakan metode elemen hingga dengan bantuan komputer (Stoker, 2009). Begitu juga dalam menganilsis tegangan kontak, dimana menggunakan persamaan Hertz yang mengasumsikan kontak gigi gear sebagai kontak dua permukaan silinder, tetapi perbedaan geometri gear yang cukup signifikan dengan silinder menyebabkan hasil analisis kurang akurat (Stoker, 2009).

Sari dan Santoso (2009) menyatakan bahwa metode elemen hingga adalah metode numerik yang digunakan untuk menyelesaikan permasalahan teknik dan problem matematis dari suatu gejala phisis dengan ketelitian yang dapat diterima oleh rekayasawan. Chan dkk (2006) menyebutkan bahwa FEM adalah sebuah cara yang lebih baik untuk menganalisis struktur dengan bentuk yang lebih kompleks dari pada solusi analitis menggunakan teori klasik.

Hotait dkk (2008) melakukan penelitian mengenai pengaruh misalignment dan lead crown pada helical gear terhadap tegangan bending pada gigi gear, menyebutkan bahwa hasil eksperimen dan prediksi menggunakan elemen hingga menunjukkan korelasi yang baik. Di samping itu, penelitian yang dilakukan oleh Patil dkk (2011) pada helical gear dengan membandingkan tegangan bending dari hasil eksperimen dengan $3 D$ photoelastic dan metode elemen hingga, menghasilkan kesimpulan bahwa perbedaan tegangan bendingnya $6,5 \%$ sehingga hasil perhitungan dengan metode elemen hingga dapat diterima. Begitu juga dengan penelitian yang dilakukan oleh Jebur dkk (2011) pada spur gear dengan membandingkan tegangan bending dari hasil eksperimen dengan $3 D$ photoelastic dan metode elemen hingga, bahwa metode elemen hingga dapat digunakan dalam menganalisis tegangan bending yang terjadi pada kontak antara permukaan gear pair. Alemu (2007), membandingkan tegangan von Misses pada helical gear pair hasil simulasi dengan Ansys dan perhitungan analitis menggunakan standar AGMA dimana hasil yang diperoleh memiliki perbedaan kurang dari $6 \%$ untuk setiap variabel.

Houser (2012) menggunakan model $3 D$ gear pair untuk menganalisis pengaruh helix angel terhadap root stress gigi gear. Tamminana dkk (2005) telah melakukan analisis dengan kondisi quasi statik pada deformable-body model dan membandingkan hasilnya dengan data eksperimen yang telah ada sebelumnya, dan menyimpulkan bahwa analisis dengan kondisi quasi statik pada deformable-body model dapat memprediksikan dynamic factor (DF) dan dynamic Transmision Error (DTE). Penelitian 
terhadap tegangan bending dan fatigue life pada misalignment bevel spiral gear dan hypoid gear dibawah kondisi quasi statik dengan membandingkan metode eksperimen dan teoritik (metode elemen hingga) telah dilakukan oleh Hotail (2011) dan menyimpulkan bahwa dengan menggunakan pembebanan yang realistis pada proses anlisa teoristis, dapat diperoleh hasil yang sesuai antara data yang diperoleh dari hasil eksperimen dan analisis teroritik dari pemodelan bevel dan hypoid gear, sehingga proses analisis teoritik dapat digunakan untuk memprediksikan pengaruh misalignment pada gear. Untuk menjaga keamanan operasional gear akibat pembatasan-pembatasan terhadap analisis berbagai variabel yang berpengaruh terhadap kegagalan gear, maka dilakukan penyesuaian terhadap faktor keamanan (safety factor) yang membatasi tegangan yang dizinkan untuk suatu material pada proses perencanaan gear (AGMA 901A92, 1992).

\section{Metodologi Penelitian}

Dalam pemodelan dibutuhkan data sifat mekanik material seperti :, modulus elastisitas dan poisson rasio. Dimensi geometri gear dalam pemodelan diperoleh dari hasil pengukuran terhadap roda gigi yang menjadi objek penelitian yaitu gear pair (dengan part number : 23421-KVB-900 dan 23430-KVB-900, produk Astra Honda motor).

Berdasarkann Japan Industrial Standar (JIS) dan Internasional Standizasion of organization (ISO) bahwa standar clearance gear adalah 0,25 module. Berdasarkan hal tersebut, maka perubahan jarak minimal poros roda gigi adalah 0,25 module. Oleh karena itu, dalam penelitian ini gear pair dimodelkan menjadi empat variasi yaitu dengan geometri sama, namun memiliki variasi jarak pusat roda gigi yang berbeda. Adapaun variasi jarak pusat roda gigi yang akan diselidiki pada penelitian ini adalah:

1. $52.55 \mathrm{~mm}$

2. $52.65 \mathrm{~mm}$

3. $52.75 \mathrm{~mm}$

4. $52.85 \mathrm{~mm}$

5. $52.95 \mathrm{~mm}$

6. $53.15 \mathrm{~mm}$

Pada penelitian ini, tegangan bending dan tegangan kontak dianalisis pada kondisi quasi satatis pada masing-masing roll angle yang ditentukan. roll angle yang di gunakan sebanyak lima buah untuk masing-masing variasi jarak pusat. Pada awal kontak ditetapkan sebagai roll angle $0^{\circ}$ kemudian driving gear diputar $4^{\circ}$ searah jarum jam untuk memperoleh titik kontak berikutnya yang disebut dalam analisis sebagai roll angle $4^{\circ}$, dan seterusnya.

Dalam perhitungan tegangan kontak dan tegangan bending, Ansys menggunakan metode elemen hingga. Dengan metode ini struktur elastis kontinu dibagi menjadi elemen atau substruktur dengan ukuran kecil. Kemudian dengan menggunakan matriks, defleksi dari tiap titik dihubungkan dengan pembebanan, sifat material, properti geometris dan lain-lainnya. Adapun langkah analisis yang digunakan dalam software ansys dilakukan dalam tiga tahap, yaitu :

\section{A. Prepocessor}

ini yaitu:

Hal-hal yang dilakukan dalam tahap

1. Pembentukan geometri gear.

Geometri model dibentuk berdasarkan data yang diperoleh dari pengukuran dimensi gear baik driven gear atau driving gear. Dalam hal ini yang divarisikan adalah jarak pusat gear. Di samping itu, dilakukan pemodelan dengan kontak pada tiap titik kontak yang dipilih dalam masing-masing variasi jarak pusat gear untuk memperoleh tegangan bending dan tegangan kontak pada tiap titik kontak pada masing-masing variasi jaraka pusat. Dalam proses pemodelan digunakan software CAD (Computer Aided Design), kemudian model disimpan dalam bentuk file dengan extensi .sat.

2. Memasukkan data sifat mekanis material yang digunakan.

Hasil yang diperoleh dari pengujian kekerasan Vickers pada material gear bagian dalam, digunakan sebagai refrensi awal yang kemudian akan dicocokkan dengan data material yang telah tersedia dari berbagai refrensi. Kemudian, material yang dipilih berdasarkan pendekatan tersebut diasumsikan sebagai material gear yang akan dianalisis. Di samping itu dalam proses analisis material gear diasumsikan besifat homogen dan isotropi.

3. Meshing

Dalam proses meshing untuk analisis tegangan bending digunakan elemen solid 187 (tersedia pada software Ansys) dengan model 3 dimensi. Untuk analisis tegangan kontak digunakan elemen conta 174 (tersedia dalam Ansys). Proses meshing dilakukan dengan otomatis oleh 
software Ansys, dengan beberapa data yang ditentukan dalam proses meshing.

B. Solution hal yaitu :

Pada tahapan ini dilakukan beberapa

1. Pengkondisian batas

Pengkondisian batas pada penelitian ini dilakukan antara lain dengan membatasi pergerakan node pada elemen yaitu gerak tranlasi dengan arah $\mathrm{x}, \mathrm{y}$ dan $\mathrm{z}$ dibatasi nol, dan rotasi terhadap sumbu $x$ dan y di batasi nol, sehingga tidak terjadi misalignment, sedangkan gerak rotasi terhadap sumbu z dibatasi nol untuk driven gear dan tidak dibatasi untuk driving gear (driving gear memungkinkan untuk berotasi terhadap sumbu-z).

4. Pembebanan

Penelitian dilakukan pada kondisi quasi statis dimana driven gear dalam posisi statis dan driving gear dikondisikan dapat berputar terhadap sumbu z. Driving gear di-inputkan beban torsi dengan besar torsi yang diberikan merupakan ekuivaluen dengan torsi maksimal yang ditransmisikan oleh gear tersebut berdasarkan daya maksimal yang dihasilkan dalam proses pembakaran pada Honda beat (diperoleh dari data spesifikasi mesin Honda Beat). Driven gear tidak diizinkan bergerak dan hanya menahan bebean akibat kontak dari driving gear. pemberian beban torsi dilakukan dengan memberikan dua buah vektor gaya yang berlawanan arah dengan besar sama sehingga terterjadi couple pada dua gaya tersebut yang menyebabkan torsi.

2. Solve

Proses solve merupakan penyelesaian masalah yang dilakukan oleh software untuk menghitung tegangan bending dan tegangan kontak yang terjadi, berdasarkan data yang dimasukkan pada tahapan sebelumnya.

\section{General postprocessor}

Tahap ini dilakukan untuk menampilkan hasil simulasi, baik tegangan von Mises, displacement, dan lain-lain.

\section{Pembahasan}

Sesuai dengan uraian pada metodologi penelitian, untuk menentukan material yang digunakan dalam analisis tegangan gear pair, dilakukan dengan pendekatan berdasarkan hasil uji kekerasan material gear pair yang diteliti. Uji kekerasan dilakukan dengan metode vickers dengan identor diamond pyramid dan beban $60 \mathrm{~kg}$.

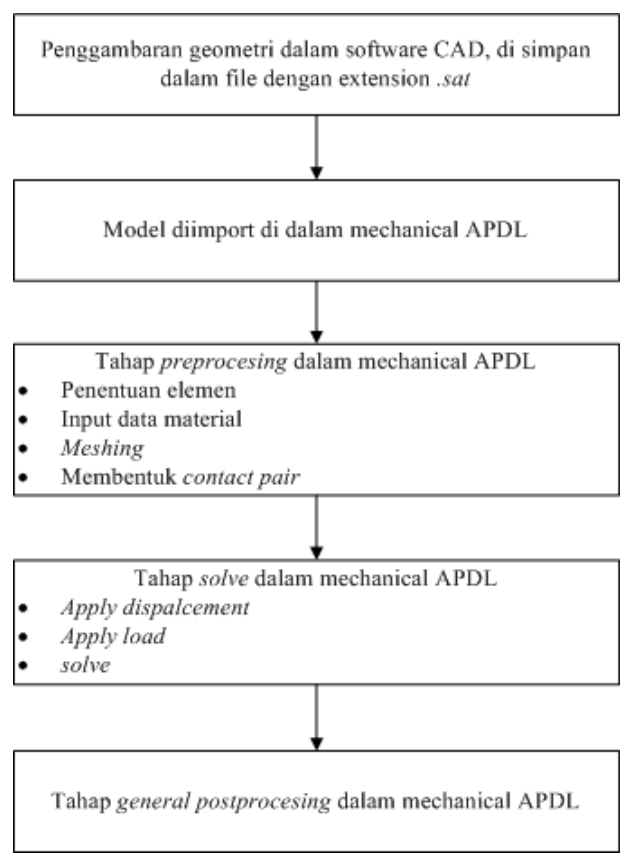

Gambar 1. Diagram alir proses pemodelan dan analisis

Harga kekerasan Vickers, driving gear $248 \mathrm{~kg} / \mathrm{mm}^{2}$ dan driven gear 271 $\mathrm{kg} / \mathrm{mm}^{2}$. Harga kekerasan yang diperoleh dari pengujian kekerasan tersebut, kemudian dikonversi menjadi nilai yield strength menggunakan persamaan 1. Dieter (1928) dan Takaya (2000) serta Kocaker (2003) menyebutkan hubungan antara kekerasan Vickers dan yield streng pada baja dapat ditunjuk kan sebagai berikut:

$$
H V=3 \times s_{y}
$$

Setelah dilakukan konversi menjadi yield strength didapatkan nilai 542.36 MPa dan $567.78 \mathrm{MPa}$. Untuk menambah bahan pertimbangan dalam penentuan material yang digunakan dalam proses simulasi, harga kekerasan Vickers material gear pair tersebut dikonversi menjadi harga kekerasan Brinell berdasarkan Standard Hardness Conversion Tables for Metals (ASTM E140-7, 2010), didapatkan harga kekerasan Brinell driving gear 238 dan driven gear 258.

Mempertimbangkan bahwa dalam produksi roda gigi dilakukan perlakuan panas terhadap roda gigi tersebut, untuk meningkatkan kekerasan permukaan roda gigi sehingga meningkatkan ketahanan terhadap keausan, maka dalam penentuan material yang digunakan dalam simulasi dipilih material dengan yield strength dibawah 
kisaran yang diperoleh dari hasil konversi di atas. Sesuai dengan Kohara (2007) dan www.efunda.com, bahwa bahan yang biasa di gunakan untuk membuat roda gigi yield strength pada kisaran data yang diperoleh berdasarkan pendekatan dengan hasil uji kekerasan di atas, maka ditentukan bahwa material yang digunakan dalam proses simulasi adalah baja S45C.

\section{A. Tegangan bending}

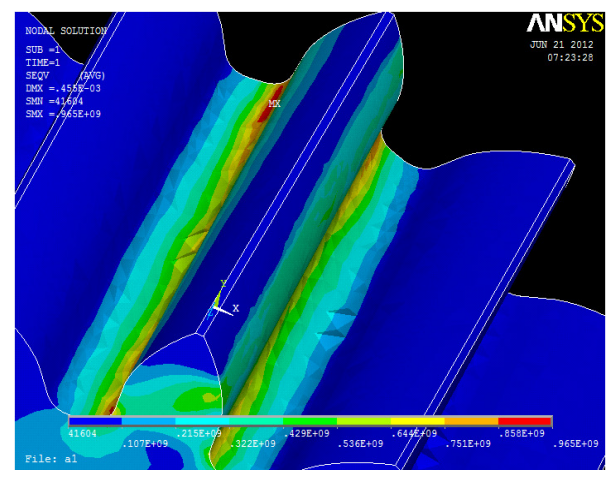

Gambar 2. tegangan vonMises bending pada driving gear, yang terjadi pada roll angle $0^{\circ}$ pada jarak sumbu poros $52,75 \mathrm{~mm}$.

Tegangan bending merupakan tegangan yang terbentuk akibat adanya momen bending. Momen bending maksimal terjadi pada bagian root fillet gear, karena dipengaruhi oleh lengan momen yang terbentuk, dimana semakin penjang lengan momen maka akan menimbulkan momen bending yang semakin besar. Dapat dilihat pada gambar 2. bahwa tegangan vonMises maksimal terjadi pada root fillet, sehingga tegangan von mises maksimal yang terjadi dapat ditetapkan sebagai tegangan bending.
Pada gambar 3 dapat dilihat bahwa variasi ke 2, 3, 4 dan 5, tegangan vonMises meningkat seiring terjadinya perninkatan roll angle. Hal ini disebabkan oleh miningkatnya roll angle menyebebkan meningkatnya lengan momen pada driving gear. Dari sebagian besar hasil simulasi pada model menunjukkan tegangan bending maksimal terjadi pada root fillet driving gear

Pada variasi ke $6(53,15 \mathrm{~mm})$ terjadi peningkatan tegangan vonMises yang cukup signifikan, gambar distribusi tegangan vonMises pada roll angle $16^{\circ}$ variasi jarak sumbu poros ke 6 dapat lihat pada gambar 4.34. dari gambar tersebut tegangan bending di root fillet sebesar $427 \mathrm{MPa}$. Hal ini disebabkan karena misalignment yang menyababkan pertambahan jarak sumbu poros menyebabkan tegangan bending pada roll angle $16^{\circ}$ meningkat, sehingga menyebabkan peningkatan momen bending, dan tegangan bending pun meningkat. Di samping itu, Tegangan vonMises maksimal terjadi pada titik bagian kontak, menunjukkan tegangan kontak yang lebih tinggi dari pada tegangan bending. Hal ini terjadi karena luasan permukaan kontak yang terjadi relativ kecil, serta kontak terjadi terjadi tidak digaris length of action sehingga sudut normal kontak berubah, dan menyebabkan gaya radial meningkat yang dapat membebani poros.

\section{B. Tegangan kontak}

Tegangan kontak terjadi pada daerah kontak dua buah permukaan. Tegangan kontak di pengaruhi oleh gaya normal dan luas permukaan kontak. Tegangan kontak berbanding terbalik dengan luas permukaan dan berbanding lurus dengan gaya normal. Tegangan kontak hasil simulasi dapat dilihat pada gambar 4.

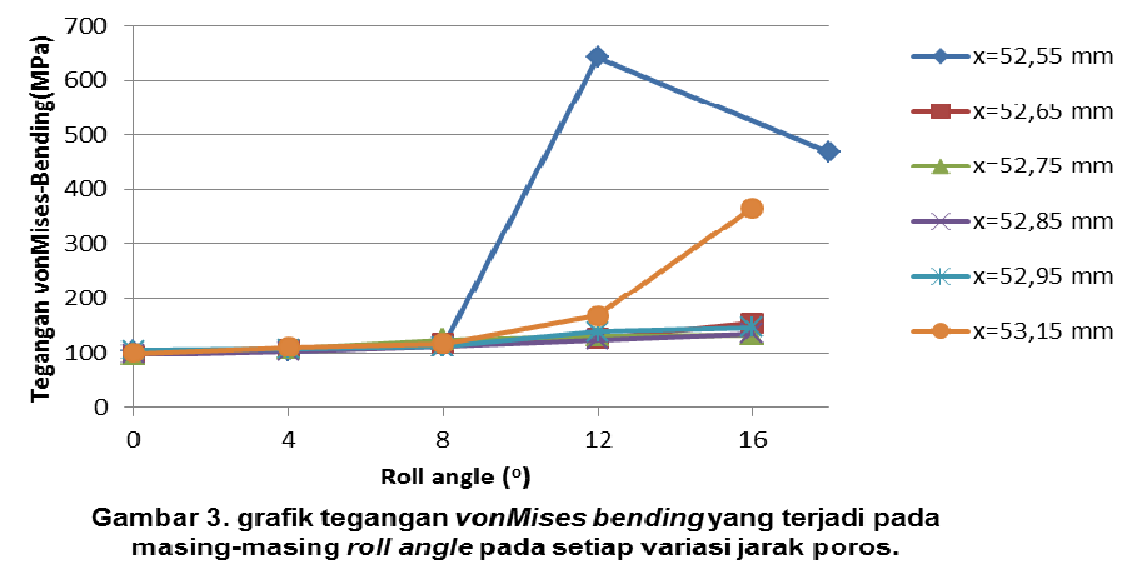




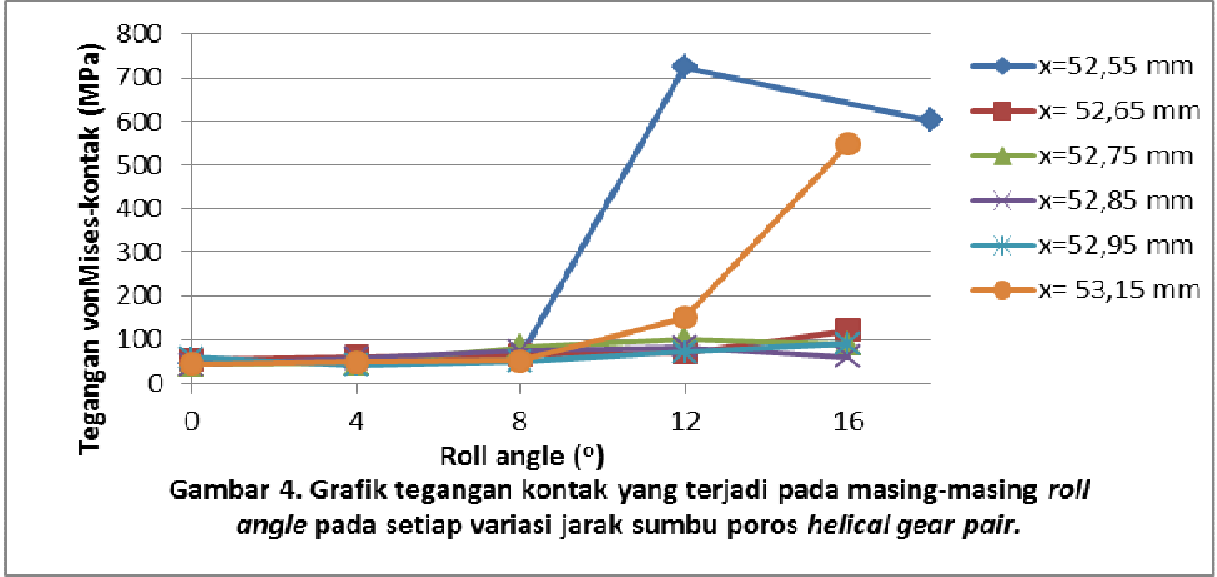

Dari 4 dapat dilihat bahwa tegangan kontak yang terbesar terjadi pada roll angle $12^{\circ}$ dengan jarak sumbu poros $52,55 \mathrm{~mm}$. Hal ini disebabkan oleh luasan permukaan kontak relative kecil yaitu pada top land driving gear akibat penyimpangan jarak sumbu poros. Pada gambar 4.35, dapat dilihat bahwa tegangan vonMises maksimum terjadi pada bagian top land driving gear dan bagian root fillet, gigi kontak 1 tersebut mengalami tegangan yang jauh lebih kecil sehingga dapat disimpulkan bahwa pada gigi tersebut komponen gaya radial lebih besar dari pada gaya tranversal. Sedangkan pada roll angle $16^{\circ}$ dengan jarak sumbu poros $53,15 \mathrm{~mm}$, tegangan kontak yang terjadi relative tinggi disebabkan oleh luasan kontak yang kecil.

\section{Perbandingan jarak sumbu poros}

Tegangan bending maksimal selalu terjadi pada root fillet sepanjang gigi tersebut kontak. Hal ini menyebabkan terjadi resiko kegagalan fatig pada root fillet gear, sedangkan tegangan kontak yang terjadi pada permukaan kontak, dengan waktu kontak tiap titik relative kecil. Oleh karena itu, pembeban pada root fillet yaitu beban bending lebih lama dari pada permukaan kontak suatu gear pair. Di sisi lain, tegangan kontak yang terjadi dapat menyebabkan keausan pada permukaan gigi gear. Semakain besar tegangan kontak menyebabkan gesekan semakin besar yang berdampak pada resiko keausan permukaan gear. Tegangan gesek yang terjadi pada permukaan gear pair berpengaruh pada efisiensi gear Vaidyanathan (2009).

Pada gambar 5. dapat dilihat bahwa faktor keamanan minimal bending terbesar dimiliki oleh variasi jarak sumbu poros 52,75 $\mathrm{mm}$, sedangkan faktor keamanan minimal kontak terbesar dimiliki oleh variasi jarak sumbu poros $52,85 \mathrm{~mm}$. Mengacu pada Neptu dan Srichandr (2010) yang ada, bahwa faktor keaman gear pair adalah lebih dari 1,75 , maka jarak sumbu poros $52,55 \mathrm{~mm}$ dan $53,15 \mathrm{~mm}$, tidak aman. Faktor keamanan minimal bending dan kontak pada jarak sumbu $52,65 \mathrm{~mm}, 52,75 \mathrm{~mm}, 52,85 \mathrm{~mm}$ dan $52,95 \mathrm{~mm}$ lebih dari 1,75 sehingga dapat disimpulkan aman dari kegagalan bending dan kontak.

Mempertimbangkan bahwa tegangan bending lebih banyak menyebabkan

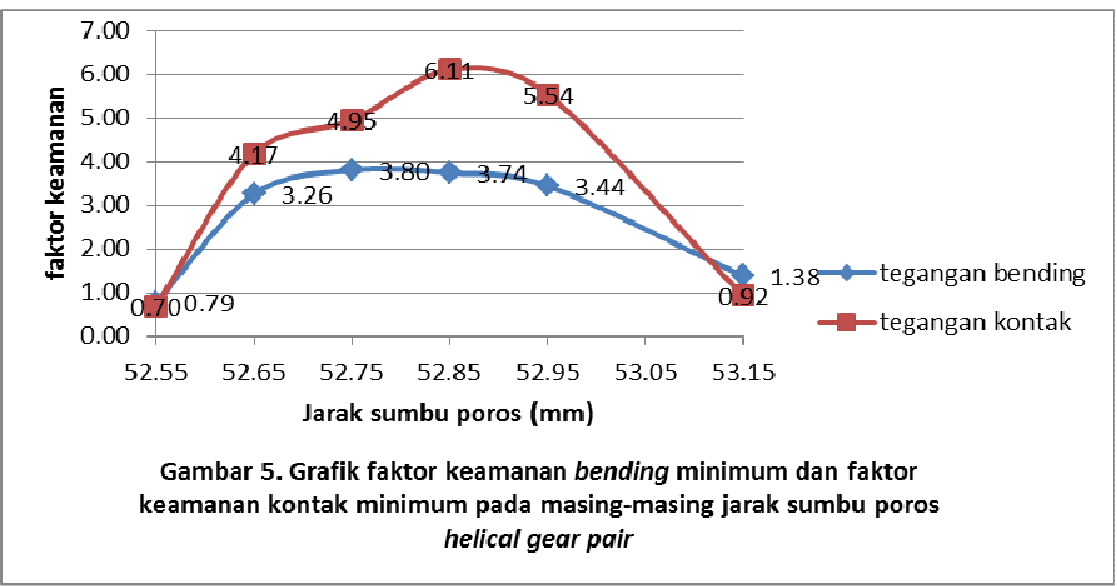


kegagalan pada gear pair dari pada tegangan kontak, maka jarak sumbu poros optimal adalah 52,75 $\mathrm{mm}$ dan 52,85 $\mathrm{mm}$. Perbedaan faktor keamanan bending antara variasi jarak sumbu poros $52,75 \mathrm{~mm}$ dengan $52,85 \mathrm{~mm}$ tidak terlalu besar yaitu 0,06, sedangkan perbedaan faktor keamanan kontak antara variasi jarak sumbu poros $52,75 \mathrm{~mm}$ dengan $52,85 \mathrm{~mm}$ cukup besar yaitu 1,16. Disamping itu dengan mempertimbangkan bahwa tegangan kontak dapat menyebabkan meningkatanya gaya gesek antara permukaan gear pair, yang berdampak pada penurunan efisiensi gear pair, maka jarak sumbu poros yang paling optimal adalah $52,85 \mathrm{~mm}$, yaitu yang memiliki tegangan kontak maksimal paling kecil di antara jarak sumbu poros yang divariasikan.

\section{Kesimpulan}

Dari hasil analisis dan pembahasan dapat disimpulkan bahwa :

1. Tegangan kontak maksimal terjadi pada jarak sumbu poros $52,55 \mathrm{~mm}$ yaitu $642,00 \mathrm{MPa}$ dan tegangan bending maksimal terjadi pada gear pair dengan jarak sumbu poros $52,55 \mathrm{~mm}$ yaitu 723,00 MPa. Besarnya tegangan kontak dan bending tersebut disebabkan oleh penyimpangan jarak sumbu poros.

2. Jarak sumbu poros $52,65 \mathrm{~mm}, 52,75$ $\mathrm{mm}, 52,85 \mathrm{~mm}$ dan 52,95 $\mathrm{mm}$ memiliki faktor keamanan yang lebih dari standar faktor keamanan operasi gear pair, sedangkan faktor keamanan pada jarak sumbu poros $52,55 \mathrm{~mm}$ dan $53,15 \mathrm{~mm}$ kurang dari standar faktor keamanan operasi gear pair. Jarak sumbu poros $52.75 \mathrm{~mm}$ merupakan jarak sumbu poros yang memiliki faktor keamanan minimal bending yang paling tinggi dan jarak sumbu poros $52.85 \mathrm{~mm}$ merupakan jarak sumbu poros yang memiliki faktor keamanan minimal kontak paling tinggi. Mempertimbangkan bahwa tegangan kontak dapat menyebabkan meningkatanya gaya gesek antara permukaan gear pair, yang berdampak pada penurunan efisiensi gear pair, maka jarak sumbu poros yang paling optimal adalah $52,85 \mathrm{~mm}$.

\section{Saran}

1. Analisis tegangan yang berbasis simulasi merupakan pendakatan awal dalam menetukan keamanan suatu perencanan, sehingga selanjutnya perlu dilakukan analisis tegangan pada gear pair yang berbasis eksperimental.
2. Penelitian ini perlu dilanjutkan dengan mengarah pada variasi fillet pada tooth root gear, mengingat pengaruh tegangan bending yang cukup besar pada kegagalan gear pair.

\section{Daftar Pustaka}

AGMA 90-A92, 1992, A Rational Procedure for the Preliminary Design of Minimum Volume Gears, American Gear Manufacturers Association: Virginia.

Alemu , N, 2007, Analysis Of Stresses In Helical Gears By Finite Element Method, Addis Ababa University

Anonim, 2007, The ABC's of Gear, Basic Gear, Kohara Gear Industry CO., LTD: Saitama Je pang

ASTM International E 140-07, 2010, Standard Hardness Conversion Tables for Metals Relationship Among Brinell Hardness, Vickers Hardness, Rockwell Hardness, Superficial Hardness, Knoop Hardness, and Scleroscope Hardness.

Chan, On Bon, Elwi, Alaa E., Grondin, Gilbert Y., 2006, Simulation Of Crack Propagation In Plat With Strain Softening Model, University Of Alberta: Alberta.

Dieter G.E. 1988. Mechanical Metallurgy, SI Metric Adition. McGraw-Hill. New York

Hotait, Mohammad A., 2011, A Theoretical and Experimental Investigation on Bending Strength and Fatigue Life of Spiral Bevel and Hypoid Gears, The Ohio State University: Ohio.

Hotait, M.A, Talbot D, and Kahraman, A., 2008, An Investigation of the Infl uence of Shaft Misalignment on Bending Stresses of Helical Gears with Lead Crown, Gear Technology November/December 2008

Houser, D. R., 2012, Helix Angle and Root Stress, The Ohio State University Gearlab.

Indrakto, R. T. 2007. Analisis Pembebanan Statik Dengan Variasi Temperature Pada Connecting Rod Motor Honda Tipe Grand 100 cc Dengan Material Baja AISI 1006, AISI 1040 dan AISI 1070 Menggunakan Software Catia v5r14. Universitas Negeri Semarang : Semarang.

Jebur, A. K., Khan, I.A. dan Nath Y. Numerical And Experimental Dynamic Contact Of Rotating Spur Gear, Modern Applied Science, Vol. 5, No. 2; April 2011 
Khurmi, R.S., and Gupta, J.K., 1982, Text Books of Machine Design, Eurasia Publishing House (Pvt) Ltd, Ram Nagar, New Delhi 110055.

Koçaker, B. ,2003, Product Properties Prediction After Forming Process Sequence, The Middle East Technical University.

Mahaputra, S. A, 2011, Sepeda Motor Terlaris Di Indonesia, http://otomotif.vivanews.com/news/rea d/248117-5-sepeda-motor-terlaris-diindonesia

Netpu, S. dan Srichandr, P., Failure Analysis of a Helical Gear, The First TSME International Conference on Mechanical Engineering,20-22 October, 2010, Ubon Ratchathani

Patil, P. Dharashiwkar, N. Joshi, K dan Jadhav, M. 2011. 3D Photoelastic And Finite Element Analysis Of Helical Gear. Machine Design, vol.3, pp. 115-120.

Sari, S. P. dan Santoso. P. 2009. Analisis Tegangan Statik Pada Rangka Sepeda Motor Jenis Matic Menggunakan Software Catia P3 V5R14. Depok, Universitas Guna Dhama.

Suprapto, H. 2012. Honda Kuasai 53\% Pasar Motor: Pertumbuhan Penjualan Motor Honda Ini Jauh Melampaui
Pertumbuhan Pasar Motor Nasional, http://otomotif. vivanews.comnewsread 279215-honda-kuasai-53--pasarmotor

Stoker, K. C., 2009, A Finite Element Approach To Spur Gear Response And Wear Under Non-Ideal Loading, University Of Florida : Florida.

Tekkaya, A. E., 2000, Relationship between Vickers Hardness and Yield Stress for Cold Formed Materials, Process Metallurgy/Metal Working/Materials, Technology Steel Research 71.

Tamminana, V. K., Kahraman, A., dan Vijayakar, S., A Study Of The Relationship Between The Dynamic Factor And The Dynamic Transmission Error Of Spur Gear Pairs,Proceedings of IDETC/CIE 2005, ASME 2005 International Design Engineering Technical Conferences and Computers and Information in Engineering Conference, September 24-28, 2005, Long Beach, California, USA

Vaidyanathan, A., 2009, An Experimental Investigation Of Helical Gear Efficiency, The Ohio State University.

Wei, Z., 2004. Stresses And Deformations In Involute Spur Gears By Finite Element Method. University of Saskatchewan: Saskatchewan. 